\title{
Implementing a road safety review approach for existing bus stops
}

\author{
M. Tiboni \& S. Rossetti \\ Department of Civil Engineering, Architecture, Land, Environment and \\ Mathematics (DICATAM), Brescia University, Italy
}

\begin{abstract}
Road safety inspections are becoming common practice in Europe: the directive 2008/96/EC requires Member States to implement road infrastructure safety management. The Italian Ministry for Transport and Infrastructures published a set of guidelines on road safety audits and inspections. This paper emphasizes the need of implementing safety inspections on peculiar features of the roads network: bus stops. Bus stops are crucial points of the public transport system and they contribute highly to its attractiveness, both in terms of quality, accessibility and safety levels. But, how should bus stops be properly located and designed to ensure safety for their users and, more in general, for all the road users? This paper provides a methodological approach to apply road safety inspections to existing bus stops and to analyse the results. The proposed inspection tool investigates different aspects of the stop, and it represents a preventive safety measure. It aims at analysing the bus stop, at highlighting possible safety threats before an accident takes place, and therefore at prioritising possible interventions. Furthermore, the paper describes how it is possible to handle data collected through the inspections, and how to use a Geographical Information System (GIS) to build an informative layer, and to perform further geo-referenced assessments on the safety, accessibility and quality level of each inspected bus stop. The method was successfully applied to some bus lines in the Province of Brescia (Italy).
\end{abstract}

Keywords: road safety, public transport, bus stops, safety review, safety inspections, accessibility, urban planning, transport planning. 


\section{Introduction}

\subsection{Road safety inspections: the reference framework}

In the recent years, the global attention on Road Safety issues has increased, and the essential role of preventive safety measures on road infrastructures has been established.

In 2011 the United Nations launched the Decade of Action for Road Safety 2011-2020. To achieve the goals of the decade, the World Health Organisation prepared a global plan that encourages countries to implement activities according to five pillars: Road safety management; Safer roads and mobility; Safer vehicles; Safer road users; and Post-crash response. Within the pillar "safer roads and mobility", a crucial role is played by safety assessments of existing roads infrastructure (WHO [1]).

At European level, already in 2001 a White Paper of the European Commission expressed the need to carry out safety impact assessments and road safety audits (European Commission [2]).

According to the directive 2008/96/EC on road infrastructure safety management, Member States shall ensure that road safety audits are carried out for infrastructure projects and that safety inspections are undertaken in respect of the roads in operation. Furthermore, the European directive pays particular attention to accidents data management. The EC directive applies to the TransEuropean road network, but each Member State may apply the provisions of the directive to other road transport infrastructures as well.

Considering the more recent White Paper (European Commission [3]) "Roadmap to a Single European Transport Area", the European Union aims at halving road casualties by 2020, and at moving close to zero fatalities by 2050 . Furthermore, the White Paper states the need to pay particular attention to vulnerable users such us pedestrians, cyclists and motorcyclists, including through safer infrastructure and vehicle technologies. Lastly, a communication of the European Commission (European Commission [4]) states the aim to promote the application of the relevant principles on infrastructure safety management to secondary roads of Member States, particularly through the exchange of best practices.

For all these reasons, road safety audits and inspections should become a common practice in Europe: safety inspections are an essential tool for preventing possible dangers for all road users, including vulnerable road users.

\subsection{Road safety inspections in Italy}

The Italian government, with the Legislative Decree n.35/2011 adopted the EU directive 2008/96/EC. For the moment, the Italian decree applies to the TEN network but it will be progressively extended: starting from January, $1^{\text {st }} 2016$, it will apply to the whole national network, and before December 2020 Regions and Provinces have to discipline the road safety management of local roads. 
The Legislative Decree was followed, in September 2012, by a ministerial decree (Ministry for Transport and Infrastructures [5]). The ministerial decree contains the guidelines for the safety management of road infrastructures and describes step by step how to undertake Road Safety Audits and Inspections. For the safety management of existing roads infrastructure, the ministerial guidelines mainly bases on the use of inspection tables and sheets, to be filled in by licensed auditors during steady and punctual safety inspections. Although the guidelines are presented as the reference frame not only for TEN and national roads, but for the secondary and local network as well, the proposed inspection tables never consider bus stops within the elements to evaluate.

Previously, in 2001, another set of guidelines concerning Safety Audits and Reviews was published by the Italian Ministry (Ministry for Transport and Infrastructures [6]). In that case the guidelines did not propose inspection tables and sheets, but they were structured through proper check lists to be used while performing audits and inspections. However, they did not consider bus stops as an important feature of the road as well. The only question regarding bus stops that was included in those ministerial check lists was: "Are there pedestrian crossings close to bus stops?” But, at least in our opinion, the presence of a zebra crossing close to the stop is not enough to ensure accessibility, quality and safety for all the vulnerable road users (mainly pedestrian) that approach the stop every day.

\subsection{The essential role of bus stops in the road network}

Starting from this framework, the present paper highlights the need for safety inspections of bus stops and illustrates a possible inspection methodology.

Nowadays, at least (but not only) in Italy, there are still many bus stops, especially outside the city centres, that do not satisfy minimum safety requirements. Bus stops are complex realities, and especially on interurban bus lines they are often located in problematic contexts such as roads with high traffic levels, or scarcely accessible for pedestrians. But the design of the public transport network is crucial, since it plays a key-role in daily transport sustainability (Busi [7]; Tiboni and Rossetti [8]). This is not a new issue: already in 1963 Sir Colin Buchanan argued that the most potent factor in lowering private car traffic lied in the provision of good public transport (Buchanan [9]).

Public transport is complementary to pedestrian movement and implies intermodality: bus stops are the initial and the terminal points of other types of movements and bus passengers are also vulnerable pedestrians at each end of the bus trip (Transport for London [10]; Maternini [11]; Rossetti and Tiboni [12]). Therefore, bus stops are crucial points of the public transport system and they highly contribute in increasing its attractiveness, both in terms of quality, accessibility and safety levels. Bus stops need to be carefully designed to ensure maximum safety for all the roads users, and especially for the most vulnerable. 


\section{The method}

To tackle with all the issues explained in the previous paragraphs, a research activity was carried out. The aim was to apply safety inspections, which are gradually gaining importance within the scientific literature, to bus stops, which are crucial points of the road network: stops represent specific and vulnerable sites on the roads, therefore they should be punctually inspected.

The research activity started with a bibliography review on the topic of safety and bus stops and with an assessment of accidents involving busses. Then, a tool for punctual inspections of bus stops was created: it consists in an inspection table, to be filled in by technicians during an on-site inspection. A table was preferred to check lists, as suggested by the most recent Italian guidelines (see paragraph 1.2)

The proposed inspection sheet is an essential tool for highlighting both the quantitative and the qualitative features of each bus stop. It is easy to apply (it takes less than 10 minutes for each bus stop) and its standardization guarantees a smooth running of the inspections. It is quite comprehensive and it is divided into 5 main sections: general information, road features, bus stop features, accessibility and perceived safety.

The general information section contains data such as the location of the bus stop, the day and the time of the inspection, the name of the bus stop, a map, some pictures and a scheme of the stop. Some of these data can be gathered before the inspection. A camera is needed to take some pictures of the stop. The use of a laser distance-measuring device and of a measuring tape is strongly recommended to write dimensions on the drawing of the stop, and it is useful to fill in some following sections of the table as well.

The table section on road features collects all the information regarding the road on which the bus stop is located, like the road hierarchy, the number of lanes, the speed limit, the availability of zebra crossings, of pavements, cycle lanes... Furthermore, this section contains the geometrical and dimensional aspects of the road.

The bus stops features section contains all the geometrical features of the stop itself (e.g. width and length of the stop area and of the road markings), its equipments (e.g. shelter, benches, timetables, artificial lighting...), the features of the waiting area...

The section on accessibility issues gathers information on the pedestrian and cycle paths to access the stop and on eventual interchange infrastructures.

Finally, the perceived safety section detects information regarding the context in which the stop is placed and that can increase the safety perceived by the users.

To test and apply the methodology, two demo bus lines were chosen and more than 160 bus stops were inspected. Both the demo lines are located in the Province of Brescia, in the north of Italy, where in the period 2005-2009 220 road accidents involved busses. Those accident caused 302 injuries and 11 fatalities (source: own analysis based on disaggregated data collected by the Province of Brescia - Department of Infrastructures), and they generated social 
costs for approximately 23 million Euros (source: own calculation based on average costs provided by the Italian Automobile Club in 2008). The safety inspections campaign took place between April and May 2012.

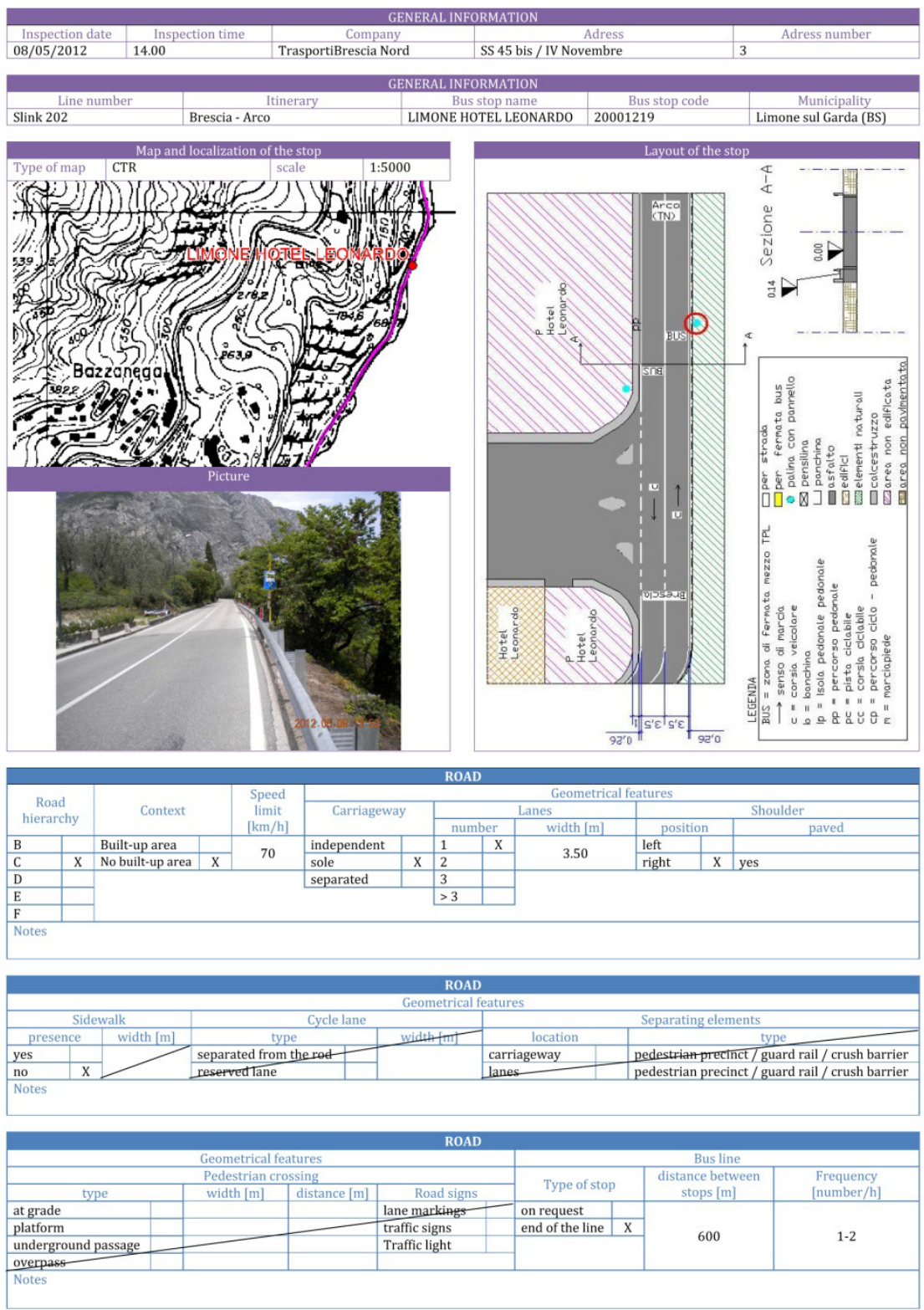

Figure 1: $\quad$ An extract of the inspection sheet (page 1 of 2). 


\section{Main findings}

Looking at the results of the inspections, it appears clearly that the situation in the Province of Brescia is not homogeneous: on one hand some bus stops are well equipped and designed, but on the other hand there also are many safety weaknesses and criticalities in the location and the design of other stops, especially outside built-up areas and where population densities are lower.

Both the inspected bus lines present some stops which are characterized by a high level of unsafety and by low accessibility (e.g. see figure 2): stops without road markings, scarcely visible and unsafely accessible by pedestrians and without parking area for cyclists. Generally, the unsafest stops are located outside urban centres and on roads with high traffic.
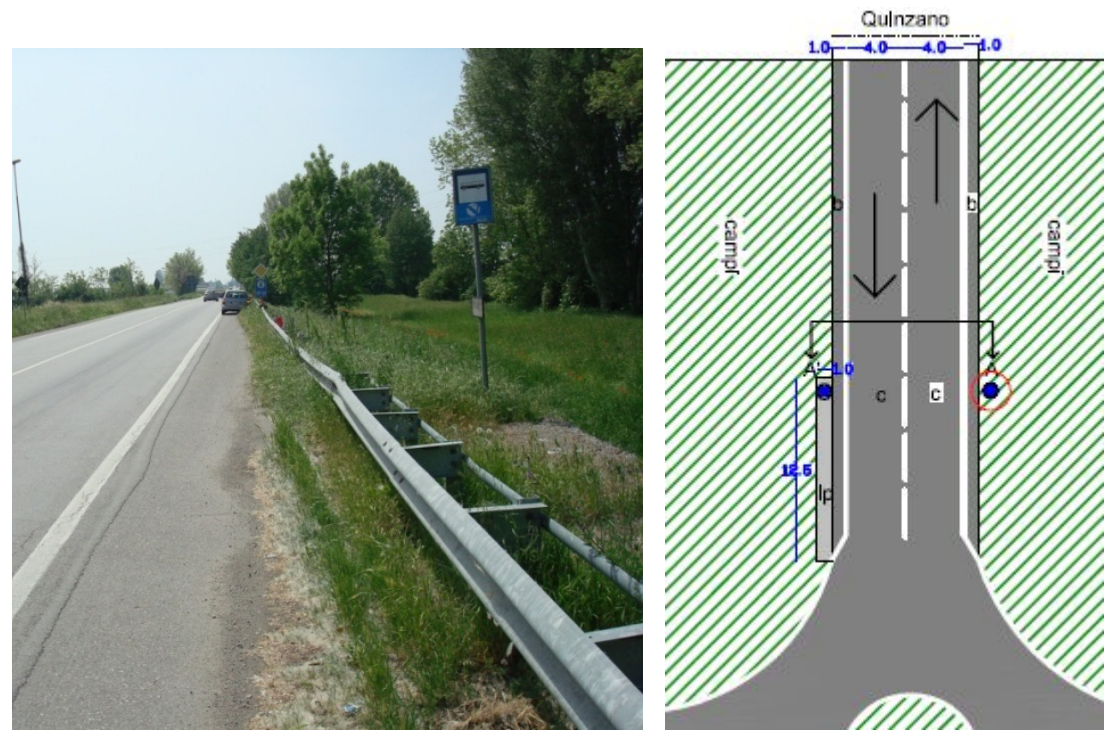

Figure 2: $\quad$ An example of an unsafe bus stop outside the urban area.

Thanks to the inspections, it was possible to collect a consistent amount of information. How is it possible to manage these data?

After having overviewed the filled-in tables, a statistical analysis was performed. Among the 166 inspected stops, 119 are located in urban areas and 43 outside urban contexts. The most critical issues concern the presence of zebra crossings: more than $30 \%$ of the bus stops do not have a marked pedestrian crossing for their users. Furthermore, in $41 \%$ of the cases there is no pavement as well. Eight percent of the inspected bus stops have no artificial lighting, which is very unsafe during the dark hours. Concerning the passengers waiting area, 54\% of the bus stops have the waiting area on the pavement, $7 \%$ on a pedestrian precinct, $34 \%$ on the road shoulder (which is the unsafest option). Looking at accessibility for vulnerable users, in $33 \%$ of the cases there is not a pedestrian path that reaches the stop, and only $25 \%$ of the inspected stops are reached by a cycle lane. 

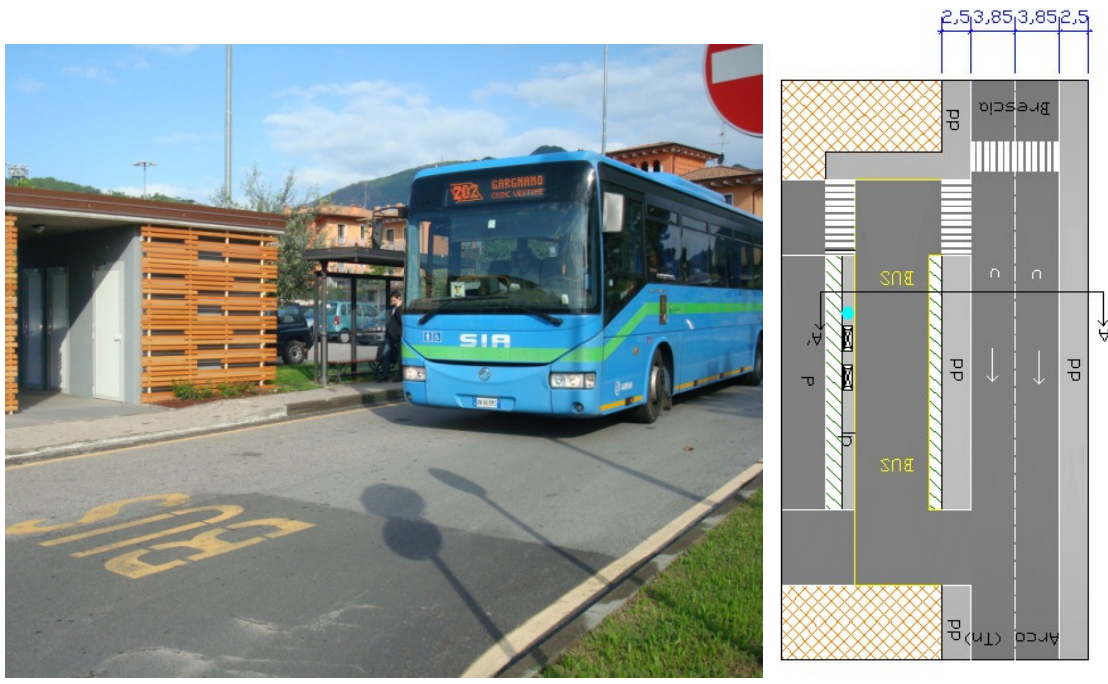

Figure 3: An example of well-equipped bus stop.

A further analysis of the results was developed looking at the spatial location of the bus stops. Using a Geographical Information System (GIS), it was possible to create a database containing all the information collected during the inspections and to link each record of the database with the exact geographical location of the related bus stop. Through this procedure, some thematic maps were created and some captions are reported in the following figures, which especially refer to some weaknesses. Thematic maps are particular helpful for decision-makers, since they provide an immediate overview of the situation, and they highlight the location of the less safe points.

A further development of the presented work, which is at the moment under implementation and validation, consists in the estimation of a unique summary index for each bus stop (or of different summary indexes for different topics like safety, accessibility, comfort...). The summary index can be estimated on a $0-1$ scale, where a higher value corresponds to a safer stop. The methodology bases on the assignment of partial scores to the elements that contribute to the quality or the safety of the bus stop. The index can be calculated using the following equation:

$$
I_{f}=\sum_{i=1}^{n} p_{i} \cdot k_{i}
$$

where:

$I_{f}$ is the final safety evaluation index that has to be estimated;

$n$ is the number of the elements that are used to assign partial scores;

$k_{i}$ is the partial score assigned to the element $i$;

$p_{i}$ is the weight assigned to the element $i$ (note that $\sum_{i=1}^{n} p_{i}=1$ ). 


\section{LEGEND}

ZEBRA
CROSSING

LACK OF
CROSSING FACILITIES

UNDERGROUND
CROSSING
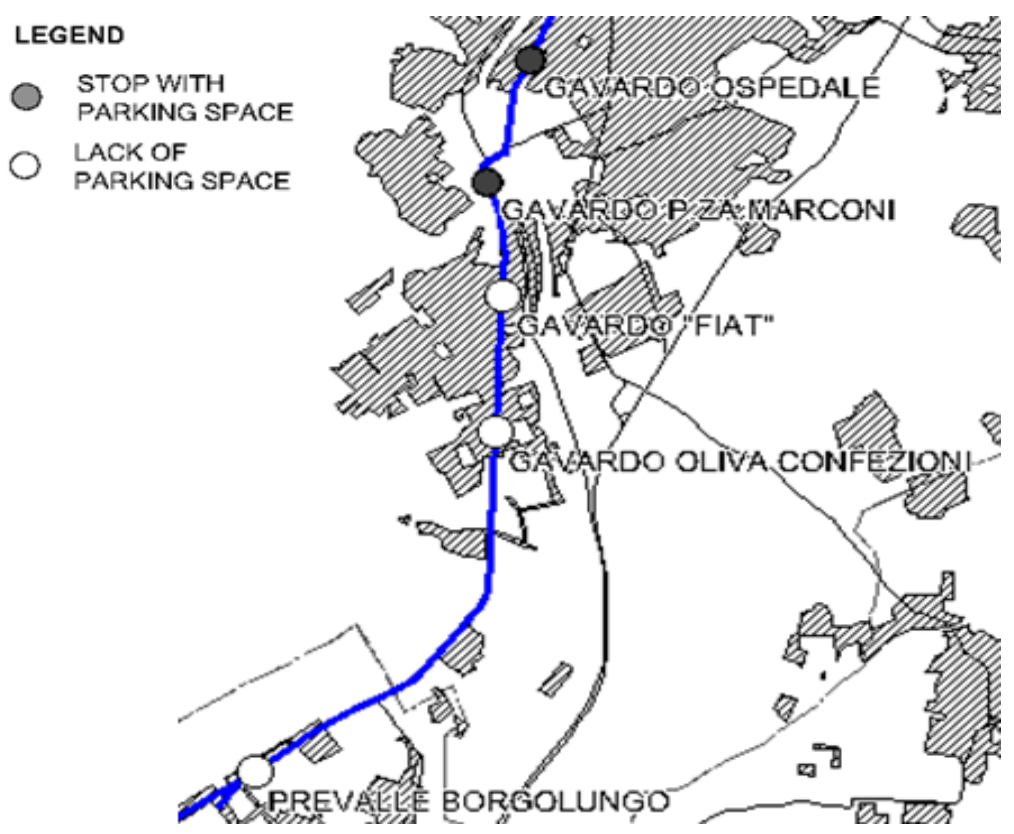
Map caption that highlights the
some of the inspected bus stops.

Figure 4: Map caption that highlights the lack of zebra crossings close to

Figure 5: Map caption that highlights the lack of car parking close to come of the inspected bus stops. 
The elements to consider, the partial scores and the weights should be defined in strong cooperation with the administrative bodies and the decision-makers that manage public transport services and road infrastructures. To provide a first sample analysis, the presence of the following elements has been considered for each bus stop: zebra crossing close to the stop, pedestrian and cycle paths that can be used to reach the stop, artificial lighting, passengers waiting area, bus stop equipment (markings, bench, shelter...); the perceived road traffic and the perceived personal security.

Using a GIS, it will be possible to link the value of the summary indexes to the location of the bus stops and to represent them in thematic maps, as shown in figure 6 .

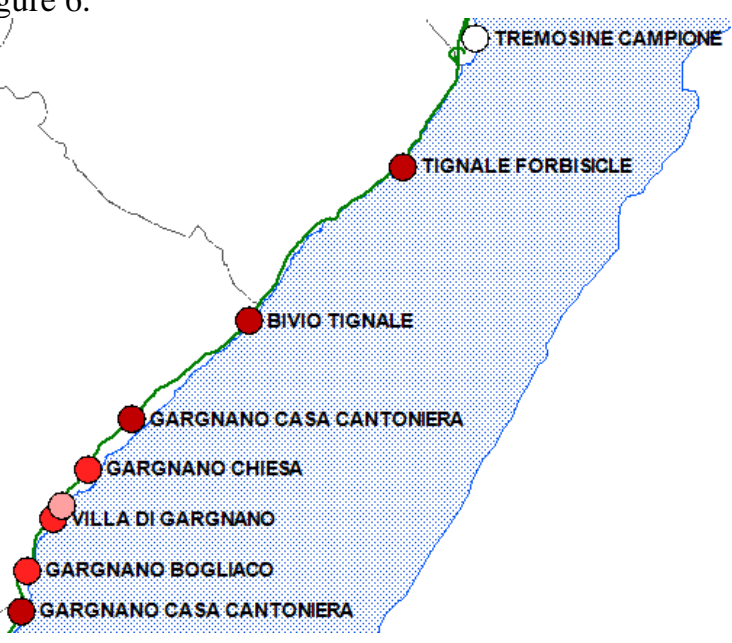

\section{LEGEND}

Safety evaluation index of the bus stops:
$0,8-1$
$0,6-0,8$
- $0,4-0,6$
- $0,2-0,4$
- $0-0,2$

Figure 6: Map caption that shows the summary evaluation index of some bus stop ( $0=$ maximum unsafety; $1=$ maximum safety).

\section{Conclusions}

The proposed methodology represents a preventive safety measure: it aims at analysing the bus stop, and at highlighting possible safety threats before an accident takes place. Thus, it helps in prioritising possible interventions. Preventive road safety analysis are able to identify the potential dangerous elements which are present along a road. Unlike road accidents analysis, which are based on the elaboration of data referred to accidents already occurred, preventive analysis are lead before the events take place (Cadei [13]).

Safety inspection of bus stops are an essential tool to assess not only road safety, but more in general, the quality of each bus stop, including accessibility, visibility, personal security, comfort, attraction basin: they do not focus only on the risks factor, but they are integrated with further information, such us the urban surrounding, the kind of services in the area, the traffic volumes... 
Therefore, they represent an useful and comprehensive tool, that is easy to apply and highlights the main criticalities. But then, a strong alliance between the political leadership and the technical management team is crucial (Tira [14]).

The creation of a georeferenced database containing the outcomes of the inspections is precious, since it helps administrative bodies in taking decisions and prioritise maintenance and infrastructural interventions, especially nowadays, when public funds are particularly scarce.

However, it has to be clear that inspections alone are not enough to ensure a proper review of bus stops safety issues. For this reason, inspections must be fully integrated with all the available diagnostic tools, such as accidents data recording, high risks site analysis, accidents scenarios... (see, among others, Fleury [15]; Tira and Ventura [16]; Busi and Tira [17]; Tiboni [18]).

Finally, although Public Transport is a fairly safe form of travel, also in this field effective safety programs should integrate various approaches (engineering, design, enforcement and encouragement) to address risks (Litman [19]).

\section{Acknowledgements}

The research was funded by the Agency of East Lombardy for Transport and Logistic ALOT s.c.a r.l., within the EU project SOL "Save Our Lives", cofinanced by the European Programme of Territorial Cooperation "Central Europe”. Furthermore, the authors acknowledge Beatrice Biemmi, Alberto Loddo, Valentina Portesani and Michele Zara for their precious help in conducting the inspections.

\section{References}

[1] World Health Organisation, Global Plan for the Decade of Action for Road Safety 2011-2020, Geneva, 2011.

[2] European Commission, White Paper. European transport policy for 2010: time to decide, Brussels, 2001.

[3] European Commission, White Paper. Roadmap to a Single European Transport Area - Towards a competitive and resource efficient transport system, Brussels, 2011.

[4] European Commission, Communication. Towards a European road safety area: policy orientations on road safety 2011-2020, Brussels, 2010.

[5] Ministero delle Infrastrutture e dei Trasporti, Linee guida per la gestione della sicurezza delle infrastrutture stradali ai sensi dell'articolo 8 del decreto legislativo 15 marzo 2011, n. 35, Gazzetta Ufficiale della Repubblica Italiana: Roma, 2012.

[6] Ministero delle Infrastrutture e dei Trasporti, Linee guida per le analisi di sicurezza delle strade, Ispettorato generale per la circolazione e la sicurezza stradale, 2001.

[7] Busi, R., Introduction: public transport to live and walk in cities. VII ${ }^{\text {th }}$ International Conference "Living and walking in cities": pedestrian 
mobility and public transport, eds. R. Busi, M. Pezzagno, Tipografia Camuna: Brescia, pp. 15-19, 2005.

[8] Tiboni, M. and Rossetti, S., The role of urban planning into a long-term climate friendly transport vision. Shaping climate friendly transport in Europe: key findings and future directions. React 2011 Proceedings, eds. Z. Radmilović, D. Čišić, University of Belgrade, Faculty of Transport and Traffic Engineering: Belgrade, pp. 161-167, 2011.

[9] Buchanan, C., Traffic in towns: a study of the long term problems of traffic in urban areas, reports of the Steering group and Working group appointed by the Minister of transport, Her Majesty's stationery office: London, 1963

[10] Transport for London, Accessible bus stop design guidance, Bus Priority Team technical advice note BP1/06, 2006.

[11] Maternini, G., Introduzione. Linee guida per la realizzazione delle fermate del trasporto pubblico locale, eds. G. Maternini, S. Foini, Egaf: Forlì, p. 11, 2009.

[12] Rossetti, S. and Tiboni, M., Suburban collective transit and land use: a methodological approach. Proceedings of the $52^{\text {nd }}$ European Congress of the RSAI, ERSA 2012 Region in Motions - Breaking the Path, Bratislava, 2012.

[13] Cadei, M., Methods for the verification and integration of the check lists in the preventive road safety analysis for vulnerable road users. XVIII ${ }^{\text {th }}$ International Conference "Living and walking in cities": sustainable mobility and road safety, eds. M. Pezzagno and S. Docchio, Egaf: Forlì, pp. 213-224, 2012.

[14] Tira, M., Sustainable management and design of urban mobility network and public space... as if safety for vulnerable road users' mattered. Safety and sustainability, ETSC: Brussels, 2005.

[15] Fleury, D., Sécurité and urbanisme. La prise en compte de la sécurité routière dans l'aménagement urbain, Presse de l'ENPC: Paris, 1998.

[16] Tira, R. and Ventura, V., Pedestrian Safety Measures in Italy, Bios: Cosenza, 2000.

[17] Busi, R. and Tira, M., Safety for pedestrians and two wheelers, Bios: Cosenza, 2001.

[18] Tiboni, M., Pianificazione urbanistica e sicurezza stradale. Dalla diagnostica alla definizione degli interventi per la mitigazione del rischio, Bios: Cosenza, 2004.

[19] Litman, T., Safer than you think! Revising the Transit Safety Narrative, Victoria Transport Policy Institute: Victoria, 2012. 